\title{
Heterogeneous Electron Transfer at Polyoxometalate-modified Electrode Surfaces
}

\author{
Suhee Choi, Bora Seo, and Jongwon Kim* \\ Department of Chemistry, Chungbuk National University, Cheongju, Chungbuk 361-763, Korea \\ *E-mail: jongwonkim@chungbuk.ac.kr \\ Received October 9, 2009, Accepted November 26, 2009
}

\begin{abstract}
The heterogeneous electron transfer at $\mathrm{SiMo}_{12} \mathrm{O}_{40}{ }^{4-}$ monolayers on GC, HOPG, and Au electrode surfaces are investigated using cyclic voltammetric and electrochemical impedance spectroscopic (EIS) methods. The electron transfer of negatively charged $\mathrm{Fe}(\mathrm{CN})_{6}{ }^{3-}$ species is retarded at $\mathrm{SiMo}_{12} \mathrm{O}_{40}{ }^{4-}$-modified electrode surfaces, while that of positively charged $\mathrm{Ru}\left(\mathrm{NH}_{3}\right)_{6}{ }^{3+}$ species is accelerated at the modified surfaces. This is due to the electrostatic interactions between $\mathrm{SiMo}_{12} \mathrm{O}_{40}{ }^{4-}$ layers on surfaces and charged redox species. The electron transfer kinetics of a neutral redox species, 1,1'ferrocenedimethanol (FDM), is not affected by the modification of electrode surfaces with $\mathrm{SiMo}_{12} \mathrm{O}_{40}{ }^{{ }^{-}}$, indicating the $\mathrm{SiMo}_{12} \mathrm{O}_{40}{ }^{4-}$ monolayers do not impart barriers to electron transfer of neutral redox species. This is different from the case of thiolate SAMs which always add barriers to electron transfer. The effect of $\mathrm{SiMo}_{12} \mathrm{O}_{40}{ }^{4-}$ layers on the electron transfer of charged redox species is dependent on the kind of electrodes, where HOPG surfaces exhibit marked effects. Possible mechanisms responsible for different electron transfer behaviors at $\mathrm{SiMo}_{12} \mathrm{O}_{40}{ }^{4-}$ layers are proposed.
\end{abstract}

Key Words: Electron transfer, Polyoxometalate, Glassy carbon, Au, HOPG

\section{Introduction}

Heterogeneous electron transfer at electrode surfaces has long been the subject of many investigations since it plays important roles in electroanalytical applications such as electrocatalysis and electrochemical sensors. Electrode kinetics is known to depend on the nature of the electrode surfaces, where the treatment methods of the electrode surfaces affect the rate of electron transfer. McCreery and co-workers intensively investigated the electron transfer behaviors at carbon based electrode surfaces such as glassy carbon (GC) and highly ordered pyrolytic graphite (HOPG). They showed that HOPG or GC surfaces can be activated for heterogeneous electron transfer by anodization or pulsed laser irradiation. ${ }^{1,2}$ The pretreatment of electrodes surfaces results in increased electron transfer rate constants $\left(k^{0}\right)$, which is ascribed to the generation of edge planes in HOPG surfaces and removal of chemi- and physisorbed impurities on GC surfaces, respectively. The electron transfer kinetics is known to be also affected by the structure of redox systems. Depending on the redox systems employed, the electron transfer occurs via either outer-sphere or inner-sphere routes which have an effect on the electron transfer rate constants. ${ }^{3-5}$

In addition to bare electrode surfaces, electron transfer behaviors at electrode surfaces modified with self-assembled monolayers (SAMs) of thiolates were widely investigated. ${ }^{6}$ The existence of organic layers on conducting electrode surfaces provides substantial barriers to heterogeneous electron transfer. ${ }^{7-9}$ It is well known that the degree of barriers for heterogeneous electron transfer is proportional to the chain length of alkanethiols. For example, SAMs of dodecanethiols on Au surfaces almost effectively block the electron transfer from an outer-sphere redox couple such as $\mathrm{Fe}(\mathrm{CN})_{6}{ }^{3-9,10}$ Introducing functional groups other than methyl groups at the end of thiols affects the electron transfer kinetics through SAMs on Au surfaces. Chidsey et al. investigated the blocking properties of thi- ols with neutral terminal groups, where the electron transfer rate constants for redox couples varies depending on the polarity of the terminal groups as well as the charge species on the redox couples. ${ }^{11}$ Ionic terminal groups substituted at the end of thiols exhibit similar but marked blocking behaviors; for negatively charged $\mathrm{Fe}(\mathrm{CN})_{6}{ }^{3-}$, electron transfer kinetics is retarded in the order of $\mathrm{NH}_{2}^{+}<\mathrm{OH}<\mathrm{COO}^{-}$terminal groups, while the response of $\mathrm{Ru}\left(\mathrm{NH}_{3}\right)_{6}{ }^{3+}$ is enhanced in the same order. ${ }^{12}$

Polyoxometalate (POM) is a large class of metal oxide molecules and has various structures, sizes, and chemical reactivities. ${ }^{13}$ POM anions are well known to spontaneously adsorb on various electrode surfaces such as $\mathrm{Au}, \mathrm{Ag}$, and carbon. ${ }^{14-16}$ Especially Keggin type POMs were widely investigated and known to forms well ordered monolayer arrays on electrode surfaces. ${ }^{17-20}$ For example, scanning tunneling microscopy images of the adsorbed monolayers of $\mathrm{SiW}_{12} \mathrm{O}_{40}{ }^{4-}$ on $\mathrm{Ag}(111)$ revealed that a four-fold square adlattice structures are formed on surfaces. ${ }^{18}$ The self-assembly of inorganic molecules can be viewed as inorganic SAMs. While the electron transfer behaviors through organic SAMs were extensively investigated, no attention has been paid to the electron transfer behaviors at inorganic SAMs on electrode surfaces. Since inorganic monolayer systems consisting of POM anions and electrode surfaces have many practical applications such as heterogeneous catalysis and electrocatalysis, ${ }^{21,22}$ it would be very desirable to elucidate the electron transfer features through inorganic SAM systems. Recently, we reported the adsorption behaviors of four different Keggin type POMs on GC and HOPG, where silicomolybdate anions $\left(\mathrm{SiMo}_{12} \mathrm{O}_{40}{ }^{4-}\right)$ adsorbed on $\mathrm{HOPG}$ exhibit unique electrochemical behaviors. ${ }^{23}$

In this report, we investigated the electron transfer behaviors through $\mathrm{SiMo}_{12} \mathrm{O}_{40}{ }^{4-}$ monolayers on $\mathrm{GC}, \mathrm{HOPG}$, and Au electrode surfaces. We utilized three redox probe molecules with different charge species, positive, neutral, and negative charges, respectively. The electron transfer behaviors of three redox pro- 
bes at $\mathrm{SiMo}_{12} \mathrm{O}_{40}{ }^{4-}$ modified electrode surfaces were examined by cyclic voltammetry and electrochemical impedance spectroscopy (EIS). Detailed electron transfer behaviors depending on either redox probes or electrode surfaces were compared with each other and possible electron transfer mechanisms are proposed.

\section{Experimental}

Chemicals. All solutions were prepared using purified water (Milli-Q, $18.2 \mathrm{M} \Omega \cdot \mathrm{cm}$ ). The supporting electrolyte was $0.1 \mathrm{M}$ $\mathrm{H}_{2} \mathrm{SO}_{4}$ (Merck). $\mathrm{H}_{4} \mathrm{SiMo}_{12} \mathrm{O}_{40}, \mathrm{~K}_{3} \mathrm{Fe}(\mathrm{CN})_{6}, \mathrm{Ru}\left(\mathrm{NH}_{3}\right)_{6} \mathrm{Cl}_{3}, 1,1$ 'ferrocenedimethanol (FDM) and all other chemicals were obtained from Aldrich and used as received. A typical concentration of electroactive species was $1 \mathrm{mM}$.

Electrode preparation and instruments. A commercially available glassy carbon (GC) electrode (CH Instrument, $3 \mathrm{~mm}$ in diameter) was employed. The surface was mechanically polished with alumina powder from a lager particle size down to a smallest one (ca. $0.05 \mu \mathrm{m})$ on a Microcloth pad (Buehler). Between each polishing step the electrode was sonicated for $5 \mathrm{~min}$ in water. HOPG was obtained from either TAAB Laboratories (Berkshire, UK) or SPI Supplies (PA, USA, SPI-1 grade equivalent to ZHA grade). Fresh basal plane surfaces were prepared by cleaving top layers using Scotch tape to give a flat, shiny surface immediately before use. This cleaving procedure resulted in variable amount of edge plane densities on the surface (vide infra). The Au substrates prepared by thermal evaporation of $5 \mathrm{~nm}$ of titanium and $200 \mathrm{~nm}$ of gold onto silicon wafers were purchased from Korea Materials \& Analysis Corp. (Korea) and cleaned for $1 \mathrm{~min}$ in piranha solution (1:3 by volume of $30 \%$ $\mathrm{H}_{2} \mathrm{O}_{2}$ and $\mathrm{H}_{2} \mathrm{SO}_{4}$, Caution: piranha solution reacts violently with most organic materials and must be handled with extreme care), rinsed with water and dried. The HOPG and Au surfaces were confined in a Viton O-ring with an inner diameter of $2.9 \mathrm{~mm}$ and used as a working electrode.

Cyclic voltammetric measurements were conducted using a BAS 100BW (Bioanalytical Systems) or CHI 660C (CH Instrument) potentiostat. Electrochemical impedance measurements were conducted using a $\mathrm{CHI} 660 \mathrm{C}$ potentiostat at the formal potential of the redox probe in the frequency range between 0.01 $\mathrm{Hz}$ and $100 \mathrm{kHz}$. All solution was purged with $\mathrm{N}_{2}$ prior to use. $\mathrm{Pt}$ wire and $\mathrm{Ag} / \mathrm{AgCl}$ electrodes were used as counter and reference electrodes, respectively. All potentials are reported relative to the $\mathrm{Ag} / \mathrm{AgCl}$ reference electrode $(3 \mathrm{M} \mathrm{KCl})$. X-ray photoelectron spectroscopy (XPS) was performed on a ESCALAB 210 spectrometer (VG Science).

Electrode modification. For modification of electrode surfaces with $\mathrm{SiMo}_{12} \mathrm{O}_{40}{ }^{4-}$ layers, the electrodes were dipped in a solution containing $1 \mathrm{mM} \mathrm{SiMo}_{12} \mathrm{O}_{40}{ }^{4-}+0.1 \mathrm{M} \mathrm{H}_{2} \mathrm{SO}_{4}$ and potential cycles were applied between $0.5 \mathrm{~V}$ and $-0.1 \mathrm{~V}$. Typical cyclic voltammograms at GC and HOPG have been previously reported $^{23}$ and that at an Au electrode is shown in the supporting information (SI, Figure S1). The electrodes were then emmersed and transferred into a pure electrolyte solution, where redox waves corresponding to $\mathrm{SiMo}_{12} \mathrm{O}_{40}{ }^{4-}$ species confined on the electrode surfaces were observed (SI, Figure S2). The surface coverage of $\mathrm{SiMo}_{12} \mathrm{O}_{40}{ }^{4-}$ on electrode surfaces can be evaluated from the charge density under the redox peaks from surface confined species. Considering that the redox waves are twoelectron processes, the surface coverages of $\mathrm{SiMo}_{12} \mathrm{O}_{40}{ }^{4-}$ at $\mathrm{GC}$, $\mathrm{Au}$, and HOPG were measured to be around $1.2 \sim 1.5 \times 10^{-10} \mathrm{~mol}$ $\mathrm{cm}^{-2}$. These values are comparable to the monolayer surface coverage of a Keggin-type POM $\left(\mathrm{AsMo}_{11} \mathrm{VO}_{40}{ }^{4-}\right)$ on $\mathrm{Au}$ and HOPG as previous reported. ${ }^{24,25}$

\section{Results}

We first note that there were some differences in cyclic voltammograms obtained from solutions containing $1 \mathrm{mM}$ $\mathrm{SiMo}_{12} \mathrm{O}_{40}{ }^{4-}+0.1 \mathrm{M} \mathrm{H}_{2} \mathrm{SO}_{4}$ at three different electrodes during the electrode modification procedures. On a GC electrode the peak separations $\left(\Delta E_{\mathrm{p}}\right)$ between cathodic and anodic waves for first and second redox couples were $38 \mathrm{mV}$ and $56 \mathrm{mV}$, respectively. On Au electrodes, the first two redox waves were observed with $\Delta E_{\mathrm{p}}$ values of $61 \mathrm{mV}$ and $71 \mathrm{mV}$, respectively. These $\Delta E_{\mathrm{p}}$ values are $c a .20 \mathrm{mV}$ larger than those observed on GC surfaces, indicating slower electron transfer kinetics on $\mathrm{Au}$ surfaces. Differently from the GC and Au surfaces, the electron transfer of $\mathrm{SiMo}_{12} \mathrm{O}_{40}{ }^{4-}$ in solution is quite retarded on a HOPG electrode. The first two redox waves almost disappear and only the third wave appears with a larger $\Delta E_{\mathrm{p}}$ value than that found on $\mathrm{GC}$ or $\mathrm{Au}$ electrode. It is known that the electron transfer kinetics of many redox species on basal plane HOPG surfaces is very slow. ${ }^{3,5}$ We checked the voltammetric response of edgeplane HOPG surfaces in $\mathrm{SiMo}_{12} \mathrm{O}_{40}{ }^{4-}$ containing solutions, which exhibited a similar cyclic voltammogram as shown in Figure S1 of SI. Therefore we assume that the retardation of electron transfer of $\mathrm{SiMo}_{12} \mathrm{O}_{40}{ }^{4-}$ species on HOPG surfaces cannot be ascribed to the inherent slow electron transfer kinetics on basal plane HOPG surfaces.

Gewirth et al. reported that $\mathrm{SiW}_{12} \mathrm{O}_{40}{ }^{4-}$ adsorbed on Ag passivates the $\mathrm{Ag}$ surfaces towards solution redox chemistry. ${ }^{26}$ This passivation is only observed on Ag surfaces, while not found on $\mathrm{Au}$ or carbon surfaces. The authors attributed this phenomenon to the formation of $\mathrm{Ag}-\mathrm{SiW}_{12} \mathrm{O}_{40}$ layers, which may act as electron transfer barriers. In this study, $\mathrm{SiMo}_{12} \mathrm{O}_{40}{ }^{4-}$ adsorbed on HOPG exhibits a similar passivation of solution redox event that was observed from $\mathrm{SiW}_{12} \mathrm{O}_{40}{ }^{4-}$ on $\mathrm{Ag}$ surfaces, while the modifications of GC and Au surfaces with $\mathrm{SiMo}_{12} \mathrm{O}_{40}{ }^{4-}$ do not change the voltammetric response of the $\mathrm{SiMo}_{12} \mathrm{O}_{40}{ }^{4-}$ in solution phase strongly.

Electrochemical behavior of $\mathrm{SiMo}_{12} \mathrm{O}_{40}{ }^{4-}$-modified electrode surfaces toward $\mathrm{Fe}(\mathrm{CN})_{6}{ }^{{ }^{-}-}$. To further investigate the electron transfer kinetics on $\mathrm{SiMo}_{12} \mathrm{O}_{40}{ }^{4-}$-modified electrode surfaces, $\mathrm{Fe}(\mathrm{CN})_{6}{ }^{3-}$ species were utilized as redox probes. Figure 1 shows cyclic voltammograms of three different electrodes obtained from a solution containing $1 \mathrm{mM} \mathrm{Fe}(\mathrm{CN})_{6}{ }^{3-}+0.1 \mathrm{M} \mathrm{H}_{2} \mathrm{SO}_{4}$. On bare $\mathrm{GC}$ and $\mathrm{Au}$ electrode surfaces, $\mathrm{Fe}(\mathrm{CN})_{6}{ }^{3-}$ couples exhibit well defined redox waves with $\Delta E_{\mathrm{p}}$ values less than $70 \mathrm{mV}$. This indicates the redox reaction of $\mathrm{Fe}(\mathrm{CN})_{6}{ }^{3-}$ is fast and reversible on these surfaces. In contrast, bare HOPG surfaces exhibited a larger $\Delta E_{\mathrm{p}}$ value of $c a .100 \mathrm{mV}$. Although this value is larger than that observed on $\mathrm{GC}$ and Au surfaces, it is quite smaller than the $\Delta E_{\mathrm{p}}$ values of basal plane HOPG surfaces with low edge plane densities previous reported. ${ }^{3,5}$ It is well known that 


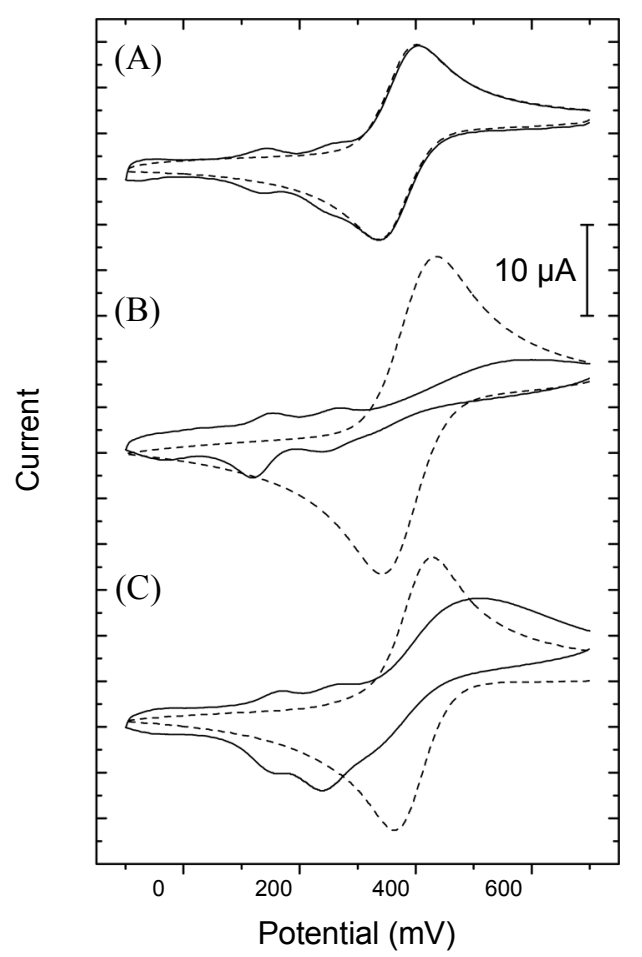

Figure 1. Cyclic voltammograms of $\mathrm{SiMo}_{12} \mathrm{O}_{40}{ }^{4-}-$ modified (solid) and bare (dashed) electrode surfaces obtained from a solution containing $1 \mathrm{mM} \mathrm{Fe}(\mathrm{CN})_{6}^{3-}+0.1 \mathrm{M} \mathrm{H}_{2} \mathrm{SO}_{4}$ (A) GC, (B) HOPG, and (C) Au electrodes. Scan rate was $50 \mathrm{mV} \mathrm{s}^{-1}$.

the electron transfer kinetics of $\mathrm{Fe}(\mathrm{CN})_{6}{ }^{3-}$ species on $\mathrm{HOPG}$ surfaces is very sensitive to the edge plane densities on HOPG and can be variable from every experiment. ${ }^{27} \mathrm{We}$ observed relatively large variations in $\Delta E_{\mathrm{p}}$ values for $\mathrm{Fe}(\mathrm{CN})_{6}{ }^{3-}$ on bare $\mathrm{HO}$ $\mathrm{PG}$ surfaces depending on cleavage procedures, which might results in different edge plane densities.

Upon the modification of electrode surfaces with $\mathrm{SiMo}_{12}-$ $\mathrm{O}_{40}{ }^{4-}$, the three electrode surfaces exhibited different electron transfer behaviors for $\mathrm{Fe}(\mathrm{CN})_{6}{ }^{3-}$ species. On $\mathrm{SiMo}_{12} \mathrm{O}_{40}{ }^{4-}$-modified GC surfaces, $\Delta E_{\mathrm{p}}$ value is $c a$. $70 \mathrm{mV}$ that is slightly larger than that observed on bare GC surfaces. This suggests that the electron transfer rate for $\mathrm{Fe}(\mathrm{CN})_{6}{ }^{3-}$ species is slightly retarded by the existence of $\mathrm{SiMo}_{12} \mathrm{O}_{40}{ }^{4-}$ layers on $\mathrm{GC}$ surfaces. We further evaluated heterogeneous electron transfer rate constants $\left(k^{0}\right)$ from the relationship between $\Delta E_{\mathrm{p}}$ values and the scan rates $(\mathrm{v})$ according to the Nicholson equation;

$$
k^{0}=\psi \frac{\left[\pi D_{O v}(n F / R T)\right]^{1 / 2}}{\left(D_{O} / D_{\mathrm{R}}\right)^{\alpha / 2}}
$$

where $D_{\mathrm{O}}$ and $D_{\mathrm{R}}$, are the diffusion coefficients of the oxidized and the reduced species, respectively; $\alpha$ is the transfer coefficient; and $n$ is the number of electron exchanged. The term $\psi$ is the transfer parameter and related to $\Delta E_{\mathrm{p}}$ and the relationship is available in the literature. ${ }^{28,29}$ The $\Delta E_{\mathrm{p}}$ values with different scan rates between 50 and $2000 \mathrm{mV} \mathrm{s}^{-1}$ have a linear relationship with square root of scan rates, from which $k^{0}$ values were evaluated (SI, Figure S3). The calculated $k^{0}$ values are listed in
Table 1. On a bare GC surface $k^{0}$ is $0.11 \mathrm{~cm} \mathrm{~s}^{-1}$, which is comparable to those previously reported. ${ }^{1,3} \mathrm{SiMo}_{12} \mathrm{O}_{40}{ }^{4-}$-modified GC surface has $k^{0}$ of $0.051 \mathrm{~cm} \mathrm{~s}^{-1}$, which is slightly smaller than that measured on a bare GC surface. This consistent with the increase $\Delta E_{\mathrm{p}}$ in cyclic voltammetric measurements, which indicates that $\mathrm{SiMo}_{12} \mathrm{O}_{40}{ }^{4-}$ layers on $\mathrm{GC}$ surfaces slightly inhibit electron transfer of $\mathrm{Fe}(\mathrm{CN})_{6}{ }^{3-}$ species.

Figure $1 \mathrm{~B}$ shows that electron transfer of $\mathrm{Fe}(\mathrm{CN})_{6}{ }^{3-}$ on $\mathrm{Si}$ $\mathrm{Mo}_{12} \mathrm{O}_{40}{ }^{4-}$-modified HOPG surfaces is highly retarded. Since the cathodic waves from $\mathrm{SiMo}_{12} \mathrm{O}_{40}{ }^{4-}$ species adsorbed on HOPG surfaces overlaps with that of $\mathrm{Fe}(\mathrm{CN})_{6}{ }^{3-}$, we estimated the cathodic peak potential of $\mathrm{Fe}(\mathrm{CN})_{6}{ }^{3-}$ by subtracting the cyclic voltammogram obtained from $\mathrm{SiMo}_{12} \mathrm{O}_{40}{ }^{4-}$-modified $\mathrm{HOPG}$ in a pure supporting electrolyte solution. The estimated $\Delta E_{\mathrm{p}}$ is $c a$. $400 \mathrm{mV}$ and this large peak separation corresponds to a quasireversible electron transfer model. The value of $k^{0}$ on a bare HOPG surface is calculated to $0.005 \mathrm{~cm} \mathrm{~s}^{-1}$, which is an order of magnitude smaller than that obtained on a bare GC surface. The $k^{0}$ value of $\mathrm{Fe}(\mathrm{CN})_{6}{ }^{3-}$ on $\mathrm{SiMo}_{12} \mathrm{O}_{40}{ }^{4-}$-modified HOPG is estimated to be less than $0.001 \mathrm{~cm} \mathrm{~s}^{-1}$ and could not be exactly evaluated by the Nicholson method due to large peak separations. It has been suggested that $k^{0}$ values for large $\Delta E_{\mathrm{p}}$ can be estimated by the simulation of extended working curve between $\Delta E_{\mathrm{p}}$ and $\log \psi .^{30}$ Based on this method, we expect $k^{0}$ value of $\mathrm{Fe}(\mathrm{CN})_{6}{ }^{3-}$ on the $\mathrm{SiMo}_{12} \mathrm{O}_{40}{ }^{4-}$ modified HOPG surface is $c a \cdot 10^{-5}$ $\mathrm{cm} \mathrm{s}^{-1}$, which is more than two orders of magnitude smaller than that observed on bare HOPG surfaces.

On Au surfaces, we also observed the inhibition of electron transfer of $\mathrm{Fe}(\mathrm{CN})_{6}{ }^{3-}$ by $\mathrm{SiMo}_{12} \mathrm{O}_{40}{ }^{4-}$ layers as shown in Figure $1 C$. In this case, the $\Delta E_{\mathrm{p}}$ is estimated to be $c a .200 \mathrm{mV}$, which is smaller than that found on HOPG surfaces modified by SiMo12$\mathrm{O}_{40}{ }^{4-}$ layers. The $k^{0}$ value on $\mathrm{SiMo}_{12} \mathrm{O}_{40}{ }^{4-}$-modified $\mathrm{Au}$ is measured to be $0.001 \mathrm{~cm} \mathrm{~s}^{-1}$. This value lies between the $k^{0}$ value measured on $\mathrm{SiMo}_{12} \mathrm{O}_{40}{ }^{4}{ }^{-}$-modified HOPG and $\mathrm{Au}$ electrode surfaces. From all of these cyclic voltammetric measurements, we conclude that electron transfer of $\mathrm{Fe}(\mathrm{CN})_{6}{ }^{3-}$ is retarded by $\mathrm{SiMo}_{12} \mathrm{O}_{40}{ }^{4-}$ layers on electrode surfaces in the order of HOPG $>$ $\mathrm{Au}>\mathrm{GC}$.

Electrochemical impedance spectroscopy (EIS) is a useful tool to describe the electron transfer behaviors across electrode surfaces. ${ }^{31}$ We performed EIS measurements on three electrode in the presence and absence of $\mathrm{SiMo}_{12} \mathrm{O}_{40}{ }^{4-}$ layers using Fe$(\mathrm{CN})_{6}^{3-}$ as a redox probe. Figure 2 shows the EIS results presented in Nyquist plots. ${ }^{29}$ The electrode processes on bare GC and $\mathrm{Au}$ electrode surfaces are mass transport limited over the whole frequency range and this fast electron transfer kinetics is consistent with the cyclic voltammetric observation as shown above. On bare HOPG surface, a semicircle located near the origin at high frequency regions indicating kinetic-controlled electron transfer is observed as shown in the inset of Figure 2B. The Randles circuit that consists of a double-layer capacitor $\left(\mathrm{C}_{\mathrm{dl}}\right)$ in parallel with a charge transfer resistor $\left(\mathrm{R}_{\mathrm{ct}}\right)$ and a Warburg impedance $(\mathrm{W})$, connected in series with a resistor measuring the resistance of the electrolyte solution $\left(R_{s}\right)$ was used to fit the impedance data. ${ }^{31}$ The $\mathrm{R}_{\mathrm{ct}}$ values of bare HOPG surface for $\mathrm{Fe}(\mathrm{CN})_{6}{ }^{3-}$ redox probes are estimated $c a .0 .3 \mathrm{k} \Omega$. This value varied depending on cleavage processes of HOPG as is the case observed in the cyclic voltammetric measurements. 

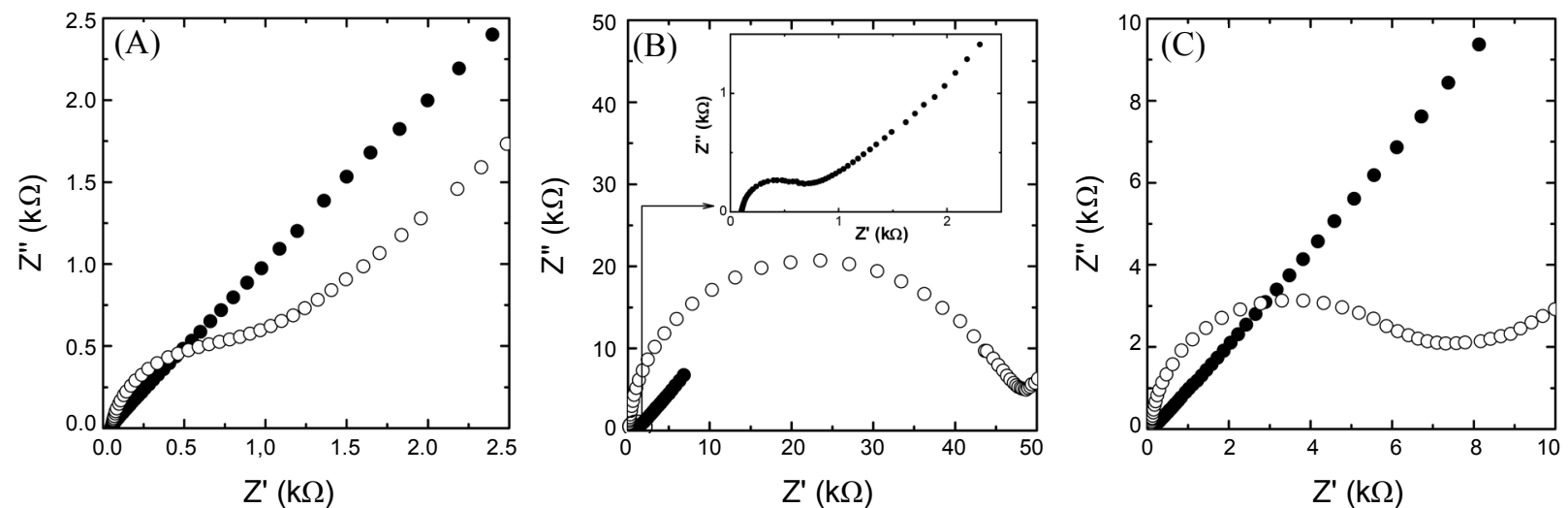

Figure 2. Nyquist plots for electrochemical impedance measurements of bare (filled circle) and $\mathrm{SiMo}_{12} \mathrm{O}_{40}{ }^{4-}{ }^{-}$modified (empty circle) electrodes in a solution containing $1 \mathrm{mM} \mathrm{Fe}(\mathrm{CN})_{6}^{3-}+0.1 \mathrm{M} \mathrm{H}_{2} \mathrm{SO}_{4}$ (A) GC, (B) HOPG, and (C) Au electrodes.

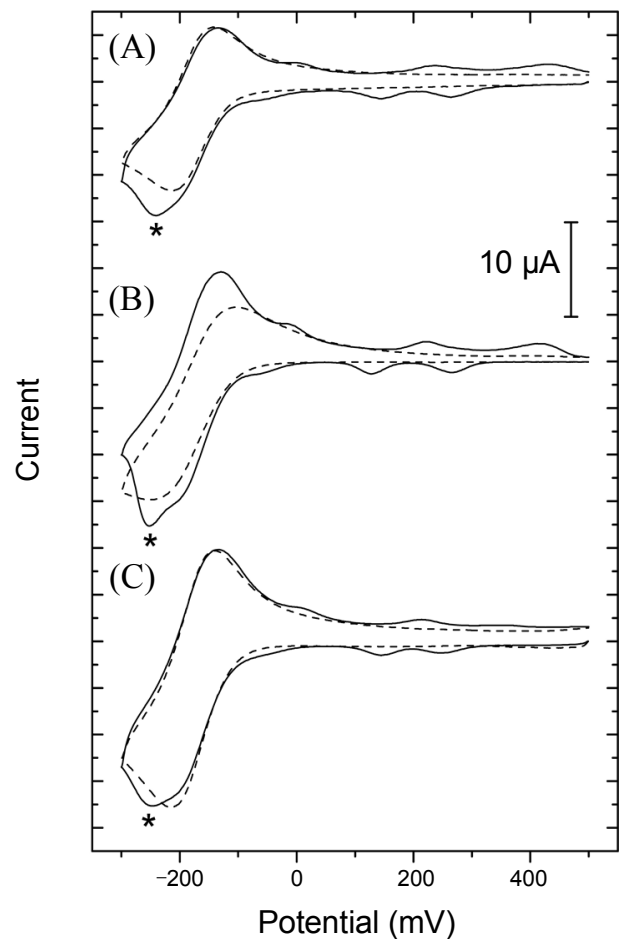

Figure 3. Cyclic voltammograms of $\mathrm{SiMo}_{12} \mathrm{O}_{40}{ }^{4-}-\operatorname{modified}($ solid) and bare (dashed) electrode surfaces obtained from a solution containing $1 \mathrm{mM} \mathrm{Ru}\left(\mathrm{NH}_{3}\right)_{6}{ }^{3+}+0.1 \mathrm{M} \mathrm{H}_{2} \mathrm{SO}_{4}$ (A) GC, (B) HOPG, and (C) Au electrodes. Scan rate was $50 \mathrm{mV} \mathrm{s}^{-1}$.

When the electrode surface is modified with $\mathrm{SiMo}_{12} \mathrm{O}_{40}{ }^{4-}$ layers, all of three electrodes exhibited kinetic controlled electron transfer behaviors. The $\mathrm{R}_{\mathrm{ct}}$ values estimated by the Randles circuit for $\mathrm{SiMo}_{12} \mathrm{O}_{40}{ }^{4-}$-modified $\mathrm{GC}, \mathrm{HOPG}$, and Au surfaces are $c a .0 .4 \mathrm{k} \Omega, 70 \mathrm{k} \Omega$, and $6 \mathrm{k} \Omega$, respectively. The variation of $\mathrm{R}_{\mathrm{ct}}$ values measured on $\mathrm{GC}$ and $\mathrm{Au}$ surfaces relative small, while HOPG surfaces gave relatively large variations in $\mathrm{R}_{\mathrm{ct}}$. Although these values are variable to a certain degree, the $\mathrm{R}_{\mathrm{ct}}$ increases in the order of $\mathrm{GC}<\mathrm{Au}<\mathrm{HOPG}$, which is well consistent with the retardation of charge transfer of $\mathrm{Fe}(\mathrm{CN})_{6}{ }^{3-}$ on three electrodes modified with $\mathrm{SiMo}_{12} \mathrm{O}_{40}{ }^{4-}$ observed by voltammetric measurements as described above.
Electrochemical behavior of $\mathrm{SiMo}_{12} \mathrm{O}_{40}{ }^{4-}$-modified electrode surfaces toward $\mathrm{Ru}\left(\mathrm{NH}_{3}\right)_{6}{ }^{3+}$ and FDM. To examine the effect of charge species of electroactive compounds, we utilized $\mathrm{Ru}$ $\left(\mathrm{NH}_{3}\right)_{6}{ }^{3+}$ and FDM as positively charged and neutral redox probes, respectively. Figure 3 shows cyclic voltammograms of three different electrodes obtained from a solution containing $1 \mathrm{mM} \mathrm{Ru}\left(\mathrm{NH}_{3}\right)_{6}{ }^{3+}+0.1 \mathrm{M} \mathrm{H}_{2} \mathrm{SO}_{4}$. Voltammetric responses of $\mathrm{Ru}\left(\mathrm{NH}_{3}\right)_{6}{ }^{3+}$ on bare electrode surfaces are similar with those of $\mathrm{Fe}(\mathrm{CN})_{6}{ }^{3-}$ species. The $\Delta E_{\mathrm{p}}$ values of $\mathrm{Ru}\left(\mathrm{NH}_{3}\right)_{6}{ }^{3+}$ on $\mathrm{GC}$ and $\mathrm{Au}$ surfaces are $c a .75 \mathrm{mV}$, while HOPG surfaces exhibits sluggish electron transfer kinetics with a $\Delta E_{\mathrm{p}}$ value of $145 \mathrm{mV}$. The voltammetric responses of $\mathrm{Ru}\left(\mathrm{NH}_{3}\right)_{6}{ }^{3+}$ on $\mathrm{SiMo}_{12} \mathrm{O}_{40}{ }^{4-}$-modified $\mathrm{GC}$ and $\mathrm{Au}$ surfaces are similar as those observed on bare surfaces. Cathodic waves appearing at around $-245 \mathrm{mV}$ (denoted by asterisks) correspond to the fourth reduction wave of $\mathrm{SiMo}_{12}-$ $\mathrm{O}_{40}{ }^{4-}$ adsorbed on electrode surfaces. ${ }^{23}$ The cathodic peak potentials of $\mathrm{Ru}\left(\mathrm{NH}_{3}\right)_{6}{ }^{3+}$ were carefully determined by correcting with background cyclic voltammograms obtained from $\mathrm{SiMo}_{12} \mathrm{O}_{40}{ }^{4-}$ modified electrode surfaces in pure electrolyte solutions. The $\Delta E_{\mathrm{p}}$ values decreased slightly, indicating the electron transfer rates of $\mathrm{Ru}\left(\mathrm{NH}_{3}\right)_{6}{ }^{3+}$ species at $\mathrm{SiMo}_{12} \mathrm{O}_{40}{ }^{4-}$ modified GC and $\mathrm{Au}$ surfaces are slightly faster than those at bare GC and Au surfaces. The $k^{0}$ values evaluated by the Nicholson method (Table 1) shows that $\mathrm{SiMo}_{12} \mathrm{O}_{40}{ }^{4-}$ layers results in an order of magnitude faster electron transfer compared with bare GC and Au surfaces. We also performed EIS measurements on GC and Au electrodes in the presence and absence of $\mathrm{SiMo}_{12} \mathrm{O}_{40}{ }^{4-}$ layers using $\mathrm{Ru}-$ $\left(\mathrm{NH}_{3}\right)_{6}{ }^{3+}$ as redox probes. However all the electrode processes were mass transport limited and no kinetic controlled electron transfer behaviors were observed (SI, Figure S4).

The effect of $\mathrm{SiMo}_{12} \mathrm{O}_{40}{ }^{4-}$ layers on the electron transfer kinetics of $\mathrm{Ru}\left(\mathrm{NH}_{3}\right)_{6}{ }^{3+}$ species is remarkable on HOPG surfaces. The $\Delta E_{\mathrm{p}}$ value on a bare HOPG surface is $c a .145 \mathrm{mV}$, which decreases to $70 \mathrm{mV}$ upon modification of $\mathrm{SiMo}_{12} \mathrm{O}_{40}{ }^{4-}$. The $k^{0}$ value of $\mathrm{Ru}\left(\mathrm{NH}_{3}\right)_{6}{ }^{3+}$ species on $\mathrm{SiMo}_{12} \mathrm{O}_{40}{ }^{4-}$-modified HOPG surfaces is at least two orders of magnitude larger than that observed on bare HOPG surfaces. Figure 4 shows EIS results on HOPG surfaces in the presence and absence of $\mathrm{SiMo}_{12} \mathrm{O}_{40}{ }^{4-}$ layers using $\mathrm{Ru}\left(\mathrm{NH}_{3}\right)_{6}{ }^{3+}$ as redox probes. On bare HOPG surfaces a semicircle indicating charge transfer limited behavior is observed at high frequency regions. The estimated $R_{c t}$ value 
Table 1. Electron transfer rate constants $\left(k^{0}, \mathrm{~cm} \mathrm{~s}^{-1}\right)$ of three redox probes at bare and $\mathrm{SiMo}_{12} \mathrm{O}_{40}{ }^{4-}$-modified electrode surfaces

\begin{tabular}{|c|c|c|c|c|c|c|}
\hline \multirow{2}{*}{$\begin{array}{l}\text { Electrode } \\
\text { Redox Probe }\end{array}$} & \multicolumn{2}{|c|}{$\mathrm{GC}$} & \multicolumn{2}{|c|}{ HOPG } & \multicolumn{2}{|c|}{$\mathrm{Au}$} \\
\hline & Bare & $\mathrm{SiMo}_{12} \mathrm{O}_{40}{ }^{4-}$ & Bare & $\mathrm{SiMo}_{12} \mathrm{O}_{40}{ }^{4-}$ & Bare & $\mathrm{SiMo}_{12} \mathrm{O}_{40}{ }^{4-}$ \\
\hline $\mathrm{Fe}(\mathrm{CN})_{6}^{3-}$ & 0.11 & 0.051 & 0.005 & $<0.001^{a}$ & 0.032 & $<0.001^{a}$ \\
\hline $\mathrm{Ru}\left(\mathrm{NH}_{3}\right)_{6}{ }^{3+}$ & 0.051 & 0.47 & $<0.001^{a}$ & 0.11 & 0.037 & 0.14 \\
\hline FDM & 0.011 & 0.012 & 0.0097 & 0.011 & 0.019 & 0.020 \\
\hline
\end{tabular}

${ }^{a}$ Cannot be exactly determined by the Nicholson method due to large peak separations.

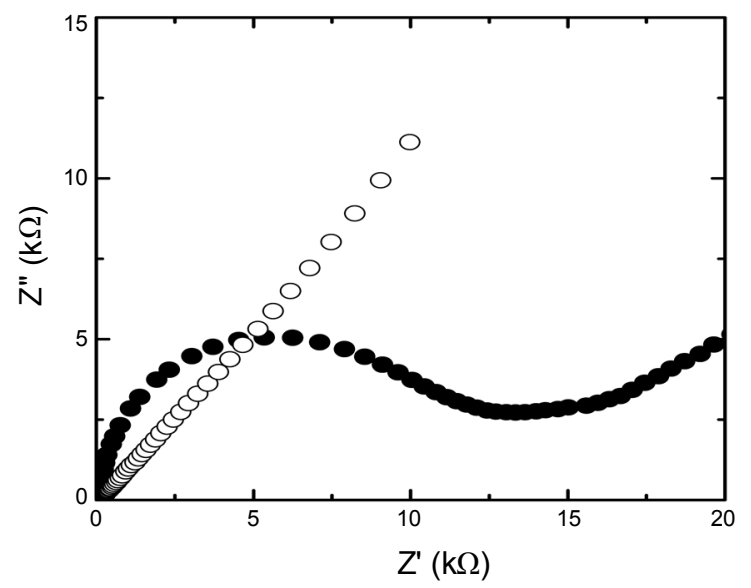

Figure 4. Nyquist plots for electrochemical impedance measurements of bare (filled circle) and $\mathrm{SiMo}_{12} \mathrm{O}_{40}{ }^{4-}$-modified (empty circle) HOPG electrodes in a solution containing $1 \mathrm{mM} \mathrm{Ru}\left(\mathrm{NH}_{3}\right)_{6}{ }^{3+}+0.1 \mathrm{M} \mathrm{H}_{2} \mathrm{SO}_{4}$.

is $c$. $10 \mathrm{k} \Omega$. In contrast, $\mathrm{SiMo}_{12} \mathrm{O}_{40}{ }^{4-}$-modified HOPG surface shows an EIS spectrum corresponding to mass transport limited electrode processes over the whole frequency range. These results support the acceleration of charge transfer kinetics of $\mathrm{Ru}$ $\left(\mathrm{NH}_{3}\right)_{6}{ }^{3+}$ species on HOPG surface after modification of surfaces with $\mathrm{SiMo}_{12} \mathrm{O}_{40}{ }^{4-}$ layers.

Figure 5 shows the voltammetric responses of neutral FDM species on bare and $\mathrm{SiMo}_{12} \mathrm{O}_{40}{ }^{4-}$-modified electrode surfaces. The cyclic voltammograms of FDM in the presence of $\mathrm{SiMo}_{12-}$ $\mathrm{O}_{40}{ }^{4-}$ layers on three electrode surfaces are same as those obtained on bare electrode surfaces. We evaluated the $k^{0}$ values of FDM on three electrode systems as listed in Table 1 . The $k^{0}$ values lies between ca. $0.01 \mathrm{~cm} \mathrm{~s}^{-1}$ and $0.02 \mathrm{~cm} \mathrm{~s}^{-1}$ and almost same values were obtained on both bare and $\mathrm{SiMo}_{12} \mathrm{O}_{40}{ }^{4-}$-modified electrode surfaces. We also performed EIS measurements, where the electrode processes of FDM at surfaces in the presence or absence of $\mathrm{SiMo}_{12} \mathrm{O}_{40}{ }^{4-}$ layers were mass transport limited and no kinetic controlled electron transfer behaviors were observed (SI, Figure S5). These results indicate that the electron transfer kinetics of a neutral FDM is not affected by $\mathrm{SiMo}_{12} \mathrm{O}_{40}{ }^{4-}$ layers on $\mathrm{GC}, \mathrm{HOPG}$, and $\mathrm{Au}$ surfaces.

Interaction between $\mathrm{SiMo}_{12} \mathrm{O}_{40}{ }^{4-}$-modified electrode surfaces and redox probe molecules. To further examine the electrochemical property of $\mathrm{SiMo}_{12} \mathrm{O}_{40}{ }^{4-}$ modified surfaces, we performed control experiments that may elucidate the interaction characteristics between $\mathrm{SiMo}_{12} \mathrm{O}_{40}{ }^{4-}$ on electrode surfaces and redox probe molecules. The results presented in Figure 1 and 2 suggest that electrostatic repulsion exists between negatively charged $\mathrm{SiMo}_{12} \mathrm{O}_{40}{ }^{4-}$ surface layers and negatively charged $\mathrm{Fe}(\mathrm{CN})_{6}^{3-}$

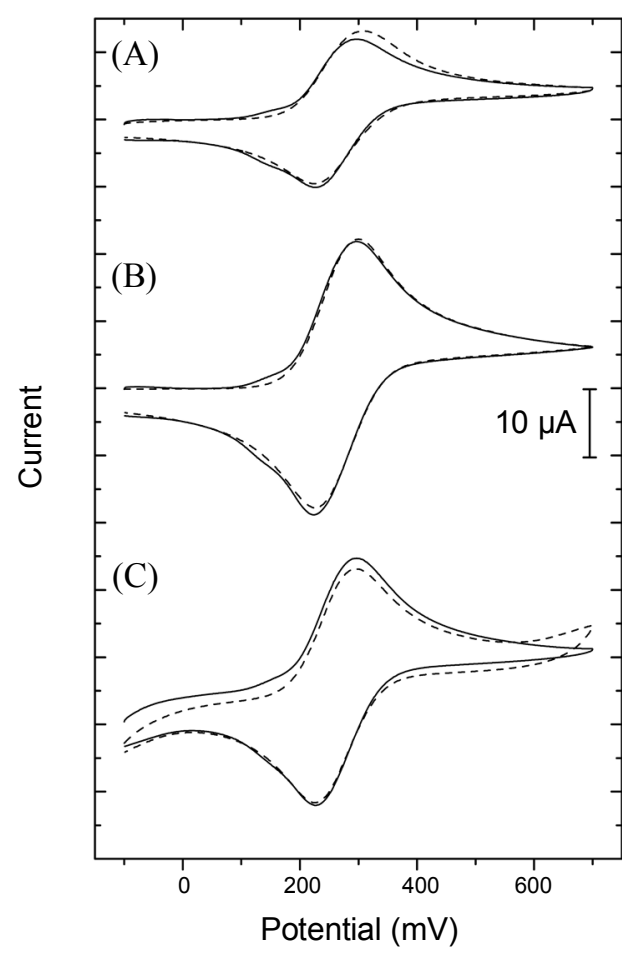

Figure 5. Cyclic voltammograms of $\mathrm{SiMo}_{12} \mathrm{O}_{40}{ }^{4-}$-modified (soild) and bare (dashed) electrode surfaces obtained from a solution containing $1 \mathrm{mM} \mathrm{FDM}+0.1 \mathrm{M} \mathrm{H}_{2} \mathrm{SO}_{4}$ (A) GC, (B) HOPG, and (C) Au electrodes. Scan rate was $50 \mathrm{mV} \mathrm{s}^{-1}$.

molecules. Figure $6 \mathrm{~A}$ shows that the electron transfer of $\mathrm{Fe}(\mathrm{CN})_{6}{ }^{3-}$ at $\mathrm{SiMo}_{12} \mathrm{O}_{40}{ }^{4-}$-modified $\mathrm{HOPG}$ surfaces is accelerated in the presence of large amount of $\mathrm{K}^{+}$in the supporting electrolyte solutions. This can be ascribed to the fact that the screening of the electrostatic repulsion between $\mathrm{Fe}(\mathrm{CN})_{6}{ }^{3-}$ and $\mathrm{SiMo}_{12} \mathrm{O}_{40}{ }^{4-}$ is caused by the addition of $\mathrm{K}^{+}$, which results in the facile electron transfer of $\mathrm{Fe}(\mathrm{CN})_{6}{ }^{3-}$ as noted by the increase of redox currents and the decrease of charge transfer resistance. A similar effect has been previously reported that the repulsion between positively charged surfaces and redox molecules can be effectively screened by the addition of negatively charged electrolyte species. $^{32}$

In the case of positively charged $\mathrm{Ru}\left(\mathrm{NH}_{3}\right)_{6}{ }^{3+}$ species, we expect electrostatic attraction between $\mathrm{SiMo}_{12} \mathrm{O}_{40}{ }^{4-}$ surface layers and $\mathrm{Ru}\left(\mathrm{NH}_{3}\right)_{6}^{3+}$. Another factor to be considered for controlling the electron transfer at electrode surfaces is the adsorption of redox active molecules on the surfaces. To examine the possible adsorption of $\mathrm{Ru}\left(\mathrm{NH}_{3}\right)_{6}{ }^{3+}, \mathrm{SiMo}_{12} \mathrm{O}_{40}{ }^{4-}$-modified HOPG surfaces is immersed in a solution containing $\mathrm{Ru}\left(\mathrm{NH}_{3}\right)_{6}{ }^{3+}$ and then 

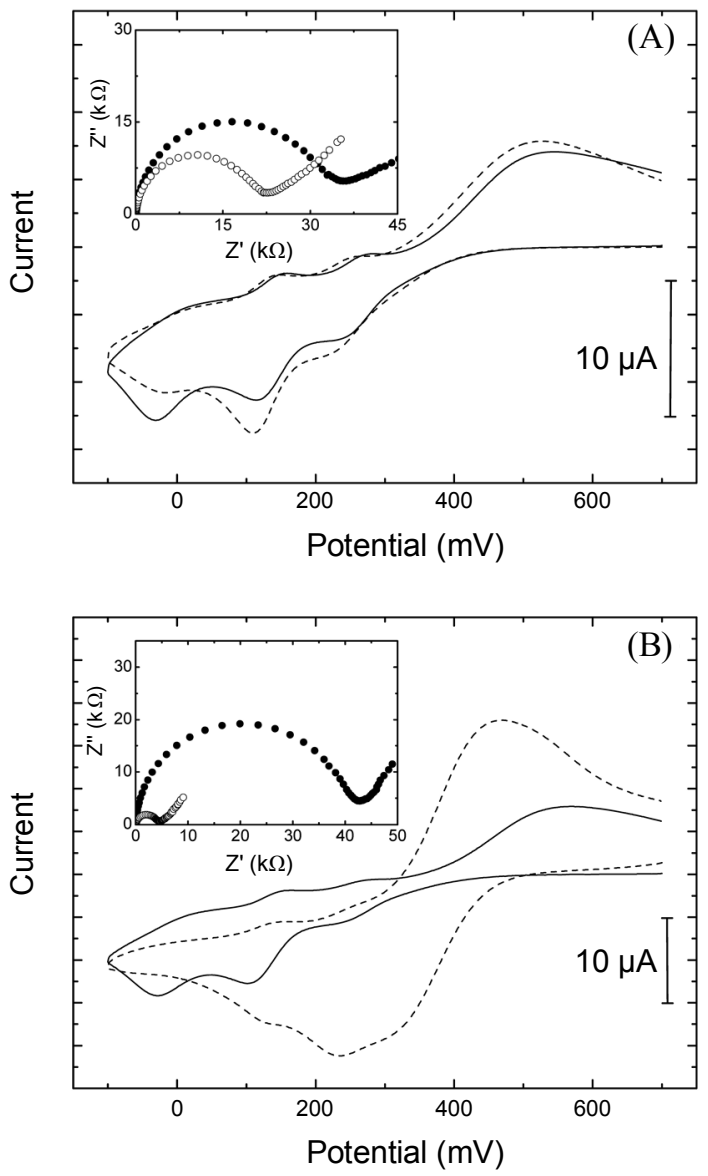

Figure 6. Cyclic voltammograms and Nyquist plots (inset) of $\mathrm{SiMo}_{12}-$ $\mathrm{O}_{40}{ }^{4-}$-modified $\mathrm{HOPG}$ electrode surfaces obtained from solutions containing $1 \mathrm{mM} \mathrm{Fe}(\mathrm{CN})_{6}{ }^{3-}+0.1 \mathrm{M} \mathrm{H}_{2} \mathrm{SO}_{4}(\mathrm{~A})$ in the absence (solid line and filled circle) and presence (dashed line and empty circle) of $50 \mathrm{mM}$ $\mathrm{K}_{2} \mathrm{SO}_{4}$ and (B) before (dashed line and empty circle) and after (solid line and filled circle) immersing the electrode in a solution containing $\mathrm{Ru}\left(\mathrm{NH}_{3}\right)_{6}{ }^{3+}$.

emersed and rinsed with pure electrolyte solution. Figure $6 \mathrm{~B}$ shows the different electron transfer behavior of $\mathrm{Fe}(\mathrm{CN})_{6}{ }^{3-}$ at $\mathrm{SiMo}_{12} \mathrm{O}_{40}{ }^{4-}$-modified HOPG surfaces before and after the immersion of the modified electrode in $\mathrm{Ru}\left(\mathrm{NH}_{3}\right)_{6}{ }^{3+}$ containing solutions. The peak separation as well as $\mathrm{R}_{\mathrm{ct}}$ decreases and the redox currents from $\mathrm{Fe}(\mathrm{CN})_{6}{ }^{3-}$ increases. These results strongly suggest that $\mathrm{Ru}\left(\mathrm{NH}_{3}\right)_{6}{ }^{3+}$ species adsorb on the $\mathrm{SiMo}_{12} \mathrm{O}_{40}{ }^{4-}-$ modified HOPG surfaces and some of them remain after emersion and rinsing. We also attempted to verify the surface confined $\mathrm{Ru}\left(\mathrm{NH}_{3}\right)_{6}{ }^{3+}$ species remaining after emersion and rinsing in a pure electrolyte solution, however, we could not clearly observe the redox wave of $\mathrm{Ru}\left(\mathrm{NH}_{3}\right)_{6}{ }^{3+}$ due to the relative small amount of remaining $\mathrm{Ru}\left(\mathrm{NH}_{3}\right)_{6}{ }^{3+}$ on the surface and the overlapping its redox waves with those of $\mathrm{SiMo}_{12} \mathrm{O}_{40}{ }^{4-}$ confined on electrode surfaces.

XPS measurements. The results presented above notify that the effect of $\mathrm{SiMo}_{12} \mathrm{O}_{40}{ }^{4-}$ layers on the electron transfer behaviors is dependent on the kind of electrode surfaces. We speculate there could be changes in oxidation state of $\mathrm{SiMo}_{12} \mathrm{O}_{40}{ }^{4}$ by interactions with different electrode surfaces. In a previous report, it was reported that the position of the W peaks in XPS

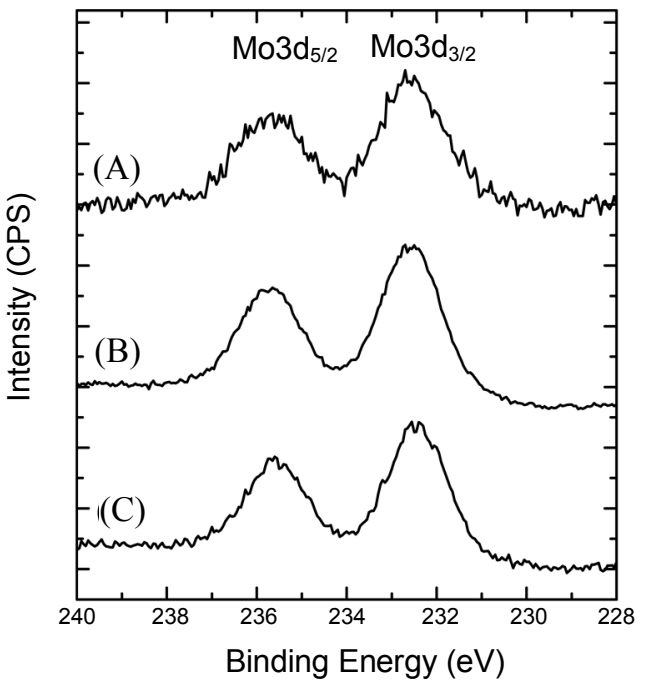

Figure 7. XPS spectra of the Mo $3 d$ region acquired from (A) GC, (B) HOPG, and (C) Au electrode surfaces modified with $\mathrm{SiMo}_{12} \mathrm{O}_{40}{ }^{4}$.

spectra obtained from $\mathrm{SiW}_{12} \mathrm{O}_{40}{ }^{4-}$ layers on $\mathrm{Ag}$ surfaces shifts by $c a .-0.15 \mathrm{eV}$ with different electrode modification procedures. ${ }^{33}$ Figure 7 shows the XPS spectra obtained from GC, $\mathrm{HOPG}$, and Au electrode surfaces modified with $\mathrm{SiMo}_{12} \mathrm{O}_{40}{ }^{4-}$. The XPS spectra confirm the existence of $\mathrm{SiMo}_{12} \mathrm{O}_{40}{ }^{4-}$ on all of three electrode surfaces, however, all the Mo peaks are observed at the same positions regardless of the substrates. The positions of $M o 3 d_{5 / 2}$ and $M o 3 d_{3 / 2}$ are $235.6 \mathrm{eV}$ and $232.6 \mathrm{eV}$, respectively. Actually the positions of Mo peaks are the same as those observed from $\mathrm{AsMo}_{11} \mathrm{VO}_{40}{ }^{4-}$ on $\mathrm{HOPG}$ surfaces as previous reported. $^{24}$

\section{Discussion}

The results presented above show that $\mathrm{SiMo}_{12} \mathrm{O}_{40}{ }^{4-}$ layers adsorbed on electrode surfaces exhibit different electron transfer behaviors depending on charge species of redox probes and the kind of electrode surfaces. In what follows, we address the intrinsic electron transfer kinetics at $\mathrm{SiMo}_{12} \mathrm{O}_{40}{ }^{4-}$-modified surfaces and the effect of redox probes and substrates on electron transfer features. We note that $\mathrm{SiMo}_{12} \mathrm{O}_{40}{ }^{4-}$-modified electrodes retain negative surface charges (vide infra), which affect the electron transfer kinetics depending on the charge species of redox probes.

Electron transfer behaviors at inorganic anion adsorbed surfaces. Comparison of voltammetric responses of neutral redox species in Figure 5 suggest that $\mathrm{SiMo}_{12} \mathrm{O}_{40}{ }^{4-}$ layers on electrode surfaces do not impart barriers to electron transfer kinetics if there is no electrostatic interaction between electrode surfaces and redox species. It is well known that SAMs of thiolates always add barriers to electron transfer. ${ }^{34}$ For alkanethiol SAMs, the charge transfer resistance increases with the length of alkyl chains. ${ }^{10,35}$ Fawcett et al. reported that $\mathrm{R}_{\mathrm{ct}}$ for electron transfer of $\mathrm{Fe}(\mathrm{CN})_{6}{ }^{3-}$ at dodecanethiol coated $\mathrm{Au}$ (111) surface is $c a .7$ $\mathrm{k} \Omega .{ }^{36}$ Neutral FDM species also experienced certain degree of barriers for electron transfer at thiolated SAMs. ${ }^{12}$ The SAMs of thiolates can be modeled as dielectric materials coating the electrode surface and reduce the electron transfer rates. Considering 
the molecular dimension of Keggin type POMs, ${ }^{13} \mathrm{SiMo}_{12} \mathrm{O}_{40}{ }^{4-}$ monolayers on electrode surfaces can viewed as inorganic thin films with a thickness of $c a .1 \mathrm{~nm}$. This inorganic layer does not add barriers to electron transfer for neutral redox species. It should be noted that electron transfer behavior of neutral FDM species would be more critically affected by the surface coverage of $\mathrm{SiMo}_{12} \mathrm{O}_{40}{ }^{4-}$ layers than that of positively or negatively charged species. In this study, we verified that the surface coverage of $\mathrm{SiMo}_{12} \mathrm{O}_{40}{ }^{4-}$ layers is close to the monolayer coverage. In a low surface coverage, electron transfer may occur between neutral FDM species and bare electrode surfaces not covered by $\mathrm{SiMo}_{12} \mathrm{O}_{40}{ }^{4-}$ layers, which do not reflect the effect of $\mathrm{SiMo}_{12}$ $\mathrm{O}_{40}{ }^{4-}$ layers on the electron transfer kinetics.

There have been few reports about the effect of adsorbed inorganic anions on the electron transfer kinetics. Ohsaka and Tokuda investigated the effect of adsorbed anions on the electron-transfer reactions of positively charged $\left[\mathrm{Co}(\text { phen })_{3}\right]^{3+}$ on platinum electrodes. ${ }^{37}$ The electron transfer kinetics is inhibited at $\mathrm{I}^{-}$-modified $\mathrm{Pt}$ surfaces, while the kinetics is accelerated at $\mathrm{SCN}^{-}$-modified $\mathrm{Pt}$ surfaces. The authors attributed the difference to the electrical double layer effect, where $\mathrm{SCN}^{-}-\mathrm{Pt}$ surfaces retain negative surface charges, while adsorbed $\mathrm{I}^{-}$is almost neutral due to its partial charge transfer. However the effect of adsorbed $\mathrm{SCN}^{-}$and $\mathrm{I}^{-}$on electron transfer is quite smaller than that observed for $\mathrm{SiMo}_{12} \mathrm{O}_{40}{ }^{4-}$-modified systems. We attribute this difference to the relative high surface charge density of $\mathrm{SiMo}_{12}$ $\mathrm{O}_{40}{ }^{4-}$-modified surfaces compared to that of $\mathrm{SCN}^{-}$or I- modified ones.

Dong et al. have reported that HOPG surfaces modified with $\mathrm{AsMo}_{11} \mathrm{VO}_{40}{ }^{4-}$ leads to a decrease of the peak currents of $\mathrm{Fe}-$ $(\mathrm{CN})_{6}{ }^{3-}$ for some extent, indicating $\mathrm{AsMo}_{11} \mathrm{VO}_{40}{ }^{4-}$ layers hinder the electron transfer of $\mathrm{Fe}(\mathrm{CN})_{6}{ }^{3-} \cdot{ }^{24}$ However, the inhibition of electron transfer of $\mathrm{Fe}(\mathrm{CN})_{6}{ }^{3-}$ on $\mathrm{AsMo}_{11} \mathrm{VO}_{40}{ }^{4-}$ modified HO$\mathrm{PG}$ surfaces is not remarkable as in the case of $\mathrm{SiMo}_{12} \mathrm{O}_{40}{ }^{4-}$ investigated in this study. The peak separations of redox waves of $\mathrm{Fe}(\mathrm{CN})_{6}{ }^{3-}$ on both of bare and $\mathrm{AsMo}_{11} \mathrm{VO}_{40}{ }^{4-}$ modified HOPG surfaces remain at the same values. In separate experiments, we observed that of $\mathrm{PMo}_{12} \mathrm{O}_{40}{ }^{3-}$ layers on $\mathrm{HOPG}$ and $\mathrm{Au}$ also inhibited the electron transfer of $\mathrm{Fe}(\mathrm{CN})_{6}{ }^{3-}$, however the degree of electron transfer inhibition is much smaller than $\mathrm{SiMo}_{12} \mathrm{O}_{40}{ }^{4-}$ layers. ${ }^{38}$ These imply that the interaction between $\mathrm{SiMo}_{12} \mathrm{O}_{40}{ }^{4-}$ and electrode surface results in a somewhat unique effect on the electron transfer kinetics compared with other POM-modified electrode systems.

Effect of charge species of redox probes on electron transfer behavior. The cyclic voltammetric results and the $k^{0}$ values listed in Table 1 as well as some EIS data illustrate that the electron transfer kinetics at $\mathrm{SiMo}_{12} \mathrm{O}_{40}{ }^{4-}$ - modified surfaces is inhibited for negatively charged $\mathrm{Fe}(\mathrm{CN})_{6}{ }^{3-}$ and accelerated for positively charged $\mathrm{Ru}\left(\mathrm{NH}_{3}\right)_{6}{ }^{3+}$ on all of three electrodes. The electron transfer of neutral FDM is not affected by modification of electrode surfaces with $\mathrm{SiMo}_{12} \mathrm{O}_{40}{ }^{4-}$. It should be noted that since the $\mathrm{H}_{4} \mathrm{SiMo}_{12} \mathrm{O}_{40}$ is known to be a very strong acid, ${ }^{13} \mathrm{Si}$ $\mathrm{Mo}_{12} \mathrm{O}_{40}{ }^{4-}$ anions exist without being protonated in supporting electrolyte solutions at $\mathrm{pH} 1$. Therefore we expect that $\mathrm{SiMo}_{12}-$ $\mathrm{O}_{40}{ }^{4-}$-modified electrodes retain negative charges on their surfaces. The negative surface charge prevents the negatively charged redox species from approaching the electrode surface clo- sely. The effect of charged functional groups in thiols constituting SAMs on the electron transfer kinetic of redox species was widely investigated. For example, 3-mercaptopropionic acid modified Au surfaces exhibit a $\mathrm{R}_{\mathrm{ct}}$ value of $0.5 \mathrm{k} \Omega$ at $\mathrm{pH} 3.5$, while the $\mathrm{R}_{\mathrm{ct}}$ increases to $65 \mathrm{k} \Omega$ at $\mathrm{pH}$, which is attributed to the increment of repulsive interaction between negatively charged carboxylate groups and $\mathrm{Fe}(\mathrm{CN})_{6}{ }^{3-}$ species at higher $\mathrm{pH}^{39}$ The effect of repulsive interaction on the retardation of electron transfer at $\mathrm{SiMo}_{12} \mathrm{O}_{40}{ }^{4-}$ - modified surfaces is also supported by the screening of negative surface charges with $\mathrm{K}^{+}$as shown in Figure 6A.

In contrast, there is electrostatic attraction between negatively charged $\mathrm{SiMo}_{12} \mathrm{O}_{40}{ }^{4-}$-modified surfaces and positively charged $\mathrm{Ru}\left(\mathrm{NH}_{3}\right)_{6}{ }^{3+}$. It is known that adsorbed anions often accelerate the electron transfer kinetics by changing a reaction pathway from the outer-sphere to the inner-sphere. ${ }^{37}$ The results shown in Figure 6B imply that there is strong interactions between $\mathrm{SiMo}_{12} \mathrm{O}_{40}{ }^{4-}$ surface layers and $\mathrm{Ru}\left(\mathrm{NH}_{3}\right)_{6}{ }^{3+}$ species. Therefore, the electron transfer of $\mathrm{Ru}\left(\mathrm{NH}_{3}\right)_{6}{ }^{3+}$ at $\mathrm{SiMo}_{12} \mathrm{O}_{40}{ }^{4-}$ modified surfaces may occur via inner-sphere route, which in turn enhances the electron transfer kinetics. A similar phenomenon has been reported that the attractive interaction between positively charged imidazole surface layers and $\mathrm{Fe}(\mathrm{CN})_{6}{ }^{3-}$ species enhances the electron transfer kinetics. ${ }^{40}$

Effect of substrates on electron transfer behavior. The effect of $\mathrm{SiMo}_{12} \mathrm{O}_{40}{ }^{4-}$ layers on electron transfer kinetics of negatively or positively charged follows a similar trend on three electrode surface, however, the degree of effect increases in the order of $\mathrm{GC}<\mathrm{Au}<\mathrm{HOPG}$. XPS measurements indicate the oxidation states of Mo in adsorbed $\mathrm{SiMo}_{12} \mathrm{O}_{40}{ }^{4-}$ are the same on three electrodes, which imply charge density experienced by charged redox species is similar. In addition, there is little difference in the surface coverages of $\mathrm{SiMo}_{12} \mathrm{O}_{40}{ }^{4-}$ estimated from the charge density under redox waves of surface confined species. One possibility that may explain the different effect of $\mathrm{SiMo}_{12} \mathrm{O}_{40}{ }^{4-}$ at three electrodes could be different adlayer structures at each electrode surface. Dong et al. reported that SAMs of AsMo 11- $_{1}$ $\mathrm{VO}_{40}{ }^{4-}$ have square and hexagonal adlayer structures on $\mathrm{Au}$ and HOPG surfaces, respectively. ${ }^{24,25}$ Different surface structures of adsorbed anions could have different charge distribution on surfaces, which may affect on the electrostatic interactions between charged surface and redox molecules.

Regarding to the remarkable effect of $\mathrm{SiMo}_{12} \mathrm{O}_{40}{ }^{4-}$ layers on electron transfer behaviors at HOPG electrodes, it should be noted that HOPG surfaces consist of two different domains; basal and edge planes. We utilized the basal plane HOPG surfaces as working electrodes throughout the experiments; however, there also exists some amount of adventitious edge planes on surfaces. The edge-plane domains on HOPG surfaces are known to sensitively affect the electron transfer of $\mathrm{Fe}(\mathrm{CN})_{6}{ }^{3-}$ and $\mathrm{Ru}\left(\mathrm{NH}_{3}\right)_{6}{ }^{3+}$ redox species. ${ }^{27}$ The effect of $\mathrm{SiMo}_{12} \mathrm{O}_{40}{ }^{4-}$ adsorption on $\mathrm{HOPG}$ surfaces on the electron transfer of the negatively or positively charged redox species is expected to be more remarkable at edge planes than at basal planes of HOPG. It has been reported that decoration of edge steps of HOPG surfaces with Au nanoparticles enhances the electron transfer of $\mathrm{Fe}(\mathrm{CN})_{6}{ }^{3-}$ species. $^{41}$ The existence of two different domains on HOPG surfaces may results in a relative large effect on electron transfer features by 
modification of $\mathrm{SiMo}_{12} \mathrm{O}_{40}{ }^{4-}$ compared with $\mathrm{GC}$ and $\mathrm{Au}$ surfaces.

\section{Conclusion}

We investigated the heterogeneous electron transfer at $\mathrm{SiMo}_{12} \mathrm{O}_{40}{ }^{4-}$ monolayers on GC, HOPG, and Au surfaces. The electron transfer of negatively charged redox species, $\mathrm{Fe}(\mathrm{CN})_{6}{ }^{3-}$, is inhibited due to the electrostatic repulsion between the Si$\mathrm{Mo}_{12} \mathrm{O}_{40}{ }^{4-}$ surface layers and redox species. In contrast, the electron transfer of positively charged $\mathrm{Ru}\left(\mathrm{NH}_{3}\right)_{6}{ }^{3+}$ species is accelerated at $\mathrm{SiMo}_{12} \mathrm{O}_{40}{ }^{4-}$ monolayers, which can be ascribed to the fact that strong attractive interactions between electrode surfaces and redox molecules provide an inner-sphere route for electron transfer. The $\mathrm{SiMo}_{12} \mathrm{O}_{40}{ }^{4-}$ monolayers on electrode surfaces do not impart barriers to electron transfer of neutral redox probe species. This is different from the case of thiolate SAMs, which are modeled as dielectric coating on the electrode surfaces, always adds barriers to electron transfer. The effect of $\mathrm{SiMo}_{12} \mathrm{O}_{40}{ }^{4-}$ layers on the electron transfer of charged redox species is more remarkable on HOPG surfaces compared with that observed on GC or Au surfaces, which might be ascribed to the existence of edge planes on HOPG surfaces. The results presented in this study would provide new insights on electron transfer at SAMs of inorganic materials.

Acknowledgments. This work was supported by the research grant of the Chungbuk National University in 2008.

Supporting Information Available. Additional cyclic voltammograms and electrochemical impedance spectroscopic data. The supporting information is available upon your request to a corresponding author (Fax: +82-43-267-2279; E-mail: jongwonkim@chungbuk.ac.kr).

\section{References}

1. Bowling, R. J.; Packard, R. T.; McCreery, R. L. J. Am. Chem. Soc. 1989, 111, 1217

2. Rice, R. J.; Pontikos, N. M.; McCreery, R. L. J. Am. Chem. Soc. 1990, $112,4617$.

3. Kneten, K. R.; McCreery, R. L. Anal. Chem. 1992, 64, 2518

4. McDermott, C. A.; Kneten, K. R.; McCreery, R. L. J. Electrochem. Soc. 1993, 140, 2593.

5. Cline, K. K.; McDermott, M. T.; McCreery, R. L. J. Phys. Chem. 1994, 98, 5314

6. Finklea, H. O. In Electroanalytical Chemistry: a Series of Advances; 1996; Vol. 19, pp 109.
7. Chidsey, C. E. D. Science 1991, 251, 919.

8. Ganesh, V.; Pal, S. K.; Kumar, S.; Lakshminarayanan, V. J. Colloid Interface Sci. 2006, 296, 195.

9. Xing, Y. F.; O'Shea, S. J.; Li, S. F. Y. J. Electroanal. Chem. 2003, $542,7$.

10. Porter, M. D.; Bright, T. B.; Allara, D. L.; Chidsey, C. E. D. J. Am. Chem. Soc. 1987, 109, 3559.

11. Chidsey, C. E. D.; Loiacono, D. N. Langmuir 1990, 6, 682.

12. Takehara, K.; Takemura, H.; Ide, Y. Electrochim. Acta 1994, 39 , 817.

13. Pope, M. T. Heteropoly and Isopoly Oxometalates; SpringerVerlag: Berlin, 1983.

14. Rong, C. Y.; Anson, F. C. Anal. Chem. 1994, 66, 3124.

15. Kuhn, A.; Anson, F. C. Langmuir 1996, 12, 5481.

16. Rong, C. Y.; Anson, F. C. Inorg. Chim. Acta 1996, 242, 11.

17. Ge, M.; Niece, B. K.; Wall, C. G.; Klemperer, W. G.; Gewirth, A. A. Mater. Res. Soc. Symp. Proc. 1997, 451, 99.

18. Lee, L.; Wang, J. X.; Adzic, R. R.; Robinson, I. K.; Gewirth, A. A. J. Am. Chem. Soc. 2001, 123, 8838.

19. Kim, J.; Gewirth, A. A. Langmuir 2003, 19, 8934.

20. Ge, M. H.; Zhong, B. X.; Klemperer, W. G.; Gewirth, A. A. J. Am. Chem. Soc. 1996, 118, 5812.

21. Sadakane, M.; Steckhan, E. Chem. Rev. 1998, 98, 219.

22. Mizuno, N.; Misono, M. Chem. Rev. 1998, 98, 199.

23. Choi, S.; Kim, J. Bull. Korean Chem. Soc. 2009, 30, 810.

24. Tang, Z. Y.; Liu, S. Q.; Wang, E. K.; Dong, S. J.; Wang, E. B. Langmuir 2000, 16, 5806

25. Tang, Z. Y.; Liu, S. Q.; Wang, E. K.; Dong, S. J. Langmuir 2000 , 16, 4946.

26. Lee, L.; Gewirth, A. A. J. Electroanal. Chem. 2002, 522, 11.

27. Xu, J. S.; Chen, Q. Y.; Swain, G. M. Anal. Chem. 1998, 70, 3146.

28. Nicholson, R. S. Anal. Chem. 1965, 37, 1351.

29. Bard, A. J.; Faulkner, L. R. Electrochemical Methods, 2nd ed.; John Wiley \& Sons: New York, 2001.

30. Mahe, E.; Devilliers, D.; Comninellis, C. Electrochim. Acta 2005, 50, 2263.

31. Park, S. M.; Yoo, J. S. Anal. Chem. 2003, 75, 455A.

32. Hwang, S.; Chi, Y. S.; Lee, B. S.; Lee, S. G.; Choi, I. S.; Kwak, J. Chem. Commun. 2006, 183.

33. Kim, J.; Lee, L.; Niece, B. K.; Wang, J. X.; Gewirth, A. A. J. Phys. Chem. B 2004, 108, 7927.

34. Love, J. C.; Estroff, L. A.; Kriebel, J. K.; Nuzzo, R. G.; Whitesides, G. M. Chem. Rev. 2005, 105, 1103 .

35. Hong, H. G.; Park, W. Langmuir 2001, 17, 2485.

36. Janek, R. P.; Fawcett, W. R.; Ulman, A. Langmuir 1998, 14, 3011.

37. Wakabayashi, N.; Kitamura, F.; Ohsaka, T.; Tokuda, K. J. Electroanal. Chem. 2001, 499, 161.

38. Choi, S.; Seo, B.; Kim, J. unpublished result.

39. Kim, K.; Kwak, J. J. Electroanal. Chem. 2001, 512, 83.

40. Hwang, S.; Lee, B. S.; Chi, Y. S.; Kwak, J.; Choi, I. S.; Lee, S. G. Electrochim. Acta 2008, 53, 2630.

41. Bastl, Z.; Franc, J.; Janda, P.; Pelouchova, H.; Samec, Z. J. Electroanal. Chem. 2007, 605, 31. 


\title{
Heterogeneous Electron Transfer at Polyoxometalate-modified Electrode Surfaces
}

\section{Suhee Choi, Bora Seo, and Jongwon Kim*}

\author{
Department of Chemistry, Chungbuk National University, Cheongju 361-763, Korea \\ *E-mail:jongwonkim@chungbuk.ac.kr \\ Received October 9, 2009, Accepted November 26, 2009
}

Key Words:

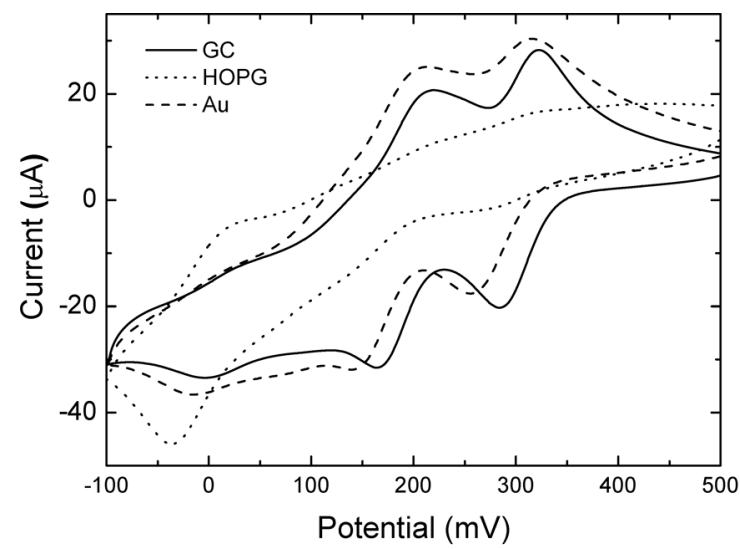

Figure S1. Cyclic voltammograms obtained from a solution containing $1 \mathrm{mM} \mathrm{SiMo}_{12} \mathrm{O}_{40}{ }^{4-}+0.1 \mathrm{M} \mathrm{H}_{2} \mathrm{SO}_{4}$ on GC, HOPG, and Au electrode surfaces. Scan rate was $50 \mathrm{mV} \mathrm{s}^{-1}$.

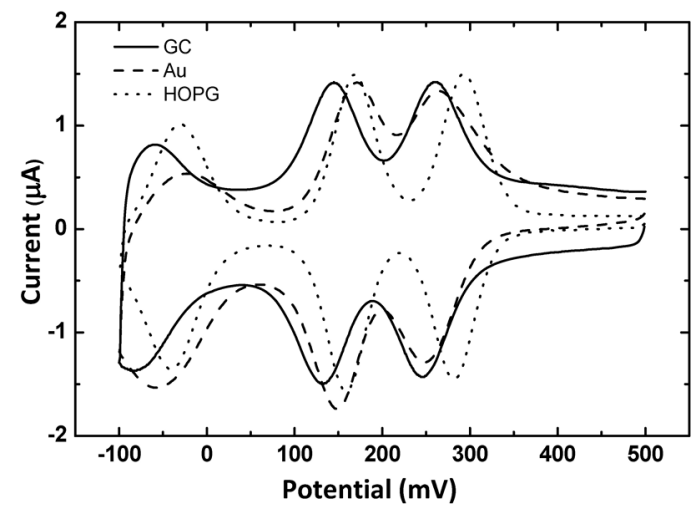

Figure S2. Cyclic voltammograms $\mathrm{SiMo}_{12} \mathrm{O}_{40}{ }^{4-}$-modified GC, HOPG, and $\mathrm{Au}$ electrode surfaces in $0.1 \mathrm{M} \mathrm{H}_{2} \mathrm{SO}_{4}$. Scan rate was $50 \mathrm{mV} \mathrm{s}^{-1}$.
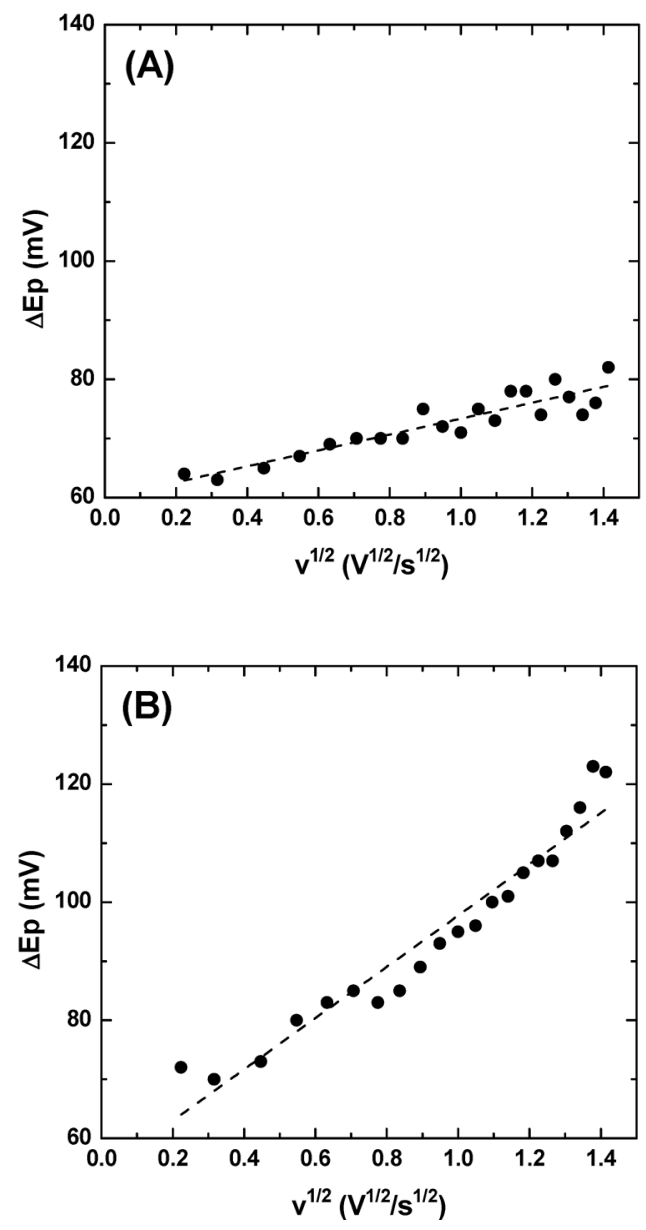

Figure S3. Variation of $\Delta E_{\mathrm{p}}$ values as a function of square root of scan rates. (A) Bare and (B) $\mathrm{SiMo}_{12} \mathrm{O}_{40}{ }^{4-}$-modified $\mathrm{GC}$ electrodes. 

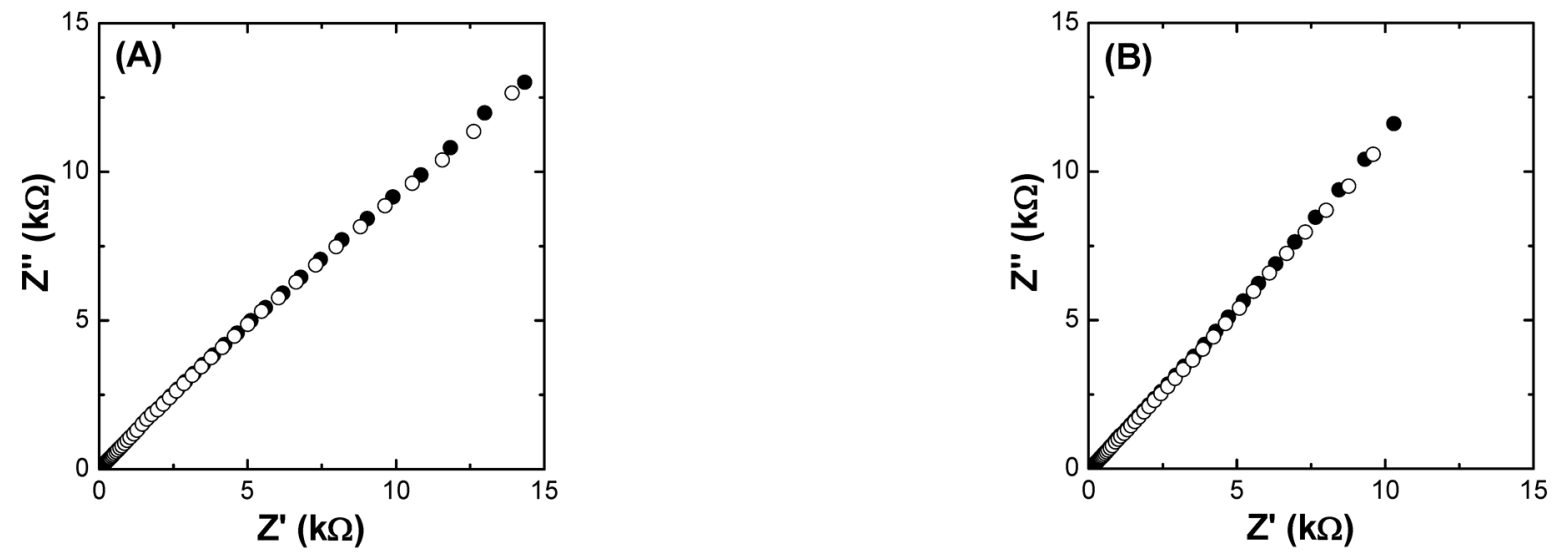

Figure S4. Nyquist plots for electrochemical impedance measurements of bare (filled) and $\mathrm{SiMo}_{12} \mathrm{O}_{40}{ }^{4-}$-modified (empty) electrodes in a solution containing $1 \mathrm{mM} \mathrm{Ru}\left(\mathrm{NH}_{3}\right)_{6}{ }^{3+}+0.1 \mathrm{M} \mathrm{H}_{2} \mathrm{SO}_{4}$ (A) $\mathrm{GC}$ and (B) Au electrodes.
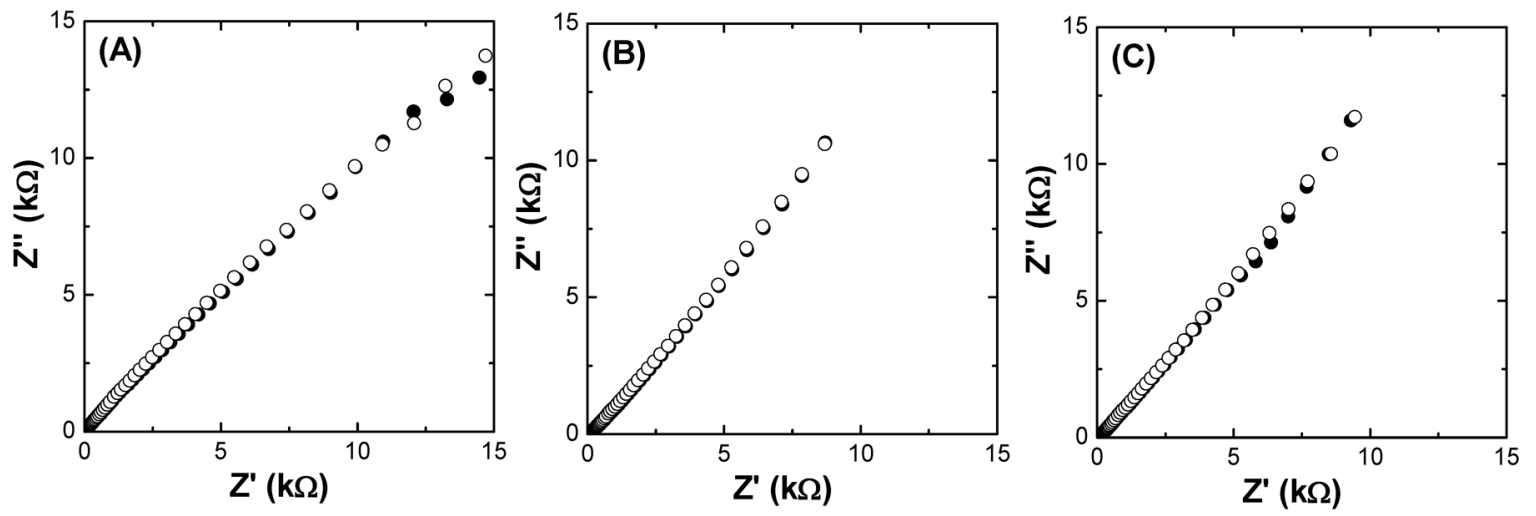

Figure S5. Nyquist plots for electrochemical impedance measurements of bare (filled) and $\mathrm{SiMo}_{12} \mathrm{O}_{40}{ }^{4-}$-modified (empty) electrodes in a solution containing $1 \mathrm{mM} \mathrm{FDM}+0.1 \mathrm{M} \mathrm{H}_{2} \mathrm{SO}_{4}$ (A) GC (B) HOPG, and (C) Au electrodes. 